\title{
Culture in psychology: Perennial problems and the contemporary methodological crisis
}

\author{
Irina A. Mironenko ${ }^{\mathrm{a}}$, Pavel S. Sorokin ${ }^{\mathrm{b}}$, \\ a Saint Petersburg State University, Saint Petersburg, Russia \\ ${ }^{b}$ National Research University Higher School of Economics, Moscow, Russia \\ *Corresponding author. E-mail: mironenko_i@mail.ru
}

\begin{abstract}
This article begins by discussing the origins of the methodological crisis in psychology. In the literature the idea of a permanent methodological crisis in psychology, lasting since the 1890s, dominates. We contest this view and argue that the contemporary methodological problems in psychology should be considered within the context of the novel and larger crisis challenging all socio-humanitarian knowledge in the face of the transformations in social reality in recent decades. The nature of these transformations and their implications for the theory and methodology of the socio-humanitarian sciences are analyzed by drawing on the sociological literature, which is more sensitive to changes in social life than is psychology.

Prominent sociologists argue that the "old" theories and interpretations of the "social" are no longer relevant in the new, highly complex, and globally unstable reality; this new reality has largely transformed the dimensions of human beings' existence. Meanwhile psychology still tends to comprehend the universal nature of the human. This position undermines the relevance of both psychology's theoretical models and the practical implications derived from these methodological assumptions.

We argue for revision of the perennial psychological problem of the biology-culture interaction in human nature. To resolve the contemporary methodological crisis in psychology, a shift is needed from theories of universal and immutable human nature to the idea of the human as an infinitely changing creature. Because culture is, primarily, the ability to change, wherein the speed and extent of changes are unique for humans, distinguishing them from other living beings.
\end{abstract}

Keywords: methodological crisis, general crisis of socio-humanitarian sciences, crisis in sociology, social reality, social transformations, biosocial problem, human nature

\section{Introduction}

Increasing dissatisfaction since the turn of the century with the methods and the corresponding theoretical thinking in psychology can be observed in international science (for example, Adair \& Vohra, 2003; Essex \& Smythe, 1999; Goertzen, 2008; 
Grace, 2001; Koltsova, 2007; Mazilov, 2006; Michell, 2003; Mironenko, 2007, 2008; Schwarz, 2009; Toomela, 2007; Valsiner, 2010; Yurevich, 1999, 2005; Zhdan, 2007; Zittoun, Gillespie, \& Cornish, 2009).

Common complaints about mainstream methodology are: fragments rather than wholes and relationships are analyzed; simple trait differences rather than complex psychological types are studied; data are not systematically related to complex theory; there is more concern with the accumulation of facts than with general theory (Toomela, 2007).

Indeed, quantitative calculations of separate parameters without necessary interpretations, on the one hand, and blurred qualitative descriptions of particulars without generalizations, on the other hand, both of which are dominant in modern mainstream research, contribute to imbuing psychological science with a growing inventory of scattered facts that do not lead to genuine understanding of human personality and essential qualities of humans. As a result we find a decrease in the prestige of psychological science, which manifests itself in methodological selfassessment of its status as a crisis as well as in a general decline in its value in public consciousness.

Understanding the origins of the current situation and identifying the causes of the crisis in contemporary psychology are necessary for finding a way out, just as treatment is impossible without a diagnosis and a remedy must address not only the symptoms but the causes of a disease.

\section{Is it still the same old crisis?}

What are the origins of the actual crisis in psychology? In the literature the idea of a permanent methodological crisis in psychology, lasting since the 1890s, dominates. As has been noted many times (Veresov 2010; Yurevich 1999, 2005; and others), assessments of methodological crises in psychology given by William James, Karl Bühler, Lev Vygotsky, and others, do not differ much from modern assessments.

Should we accept this view? Should we consider that, in psychological science for more than a century of its development, there were no changes radical enough to revise its general condition? New schools appeared; the norms and ideals of science changed in the course of the transformation of classical science into nonclassical and post-non-classical science; psychology became a mass profession, which significantly changed the ratio of academic to applied research and the structure of the professional community. Can it still be the same crisis in psychology? It hardly seems possible.

Moreover, the discourse of the renowned crisis of the late 19th century to the first third of the 20th century was and still is focused on the problem of the disunity of psychological science, on the lack of mutual understanding and constructive cooperation by theoretical schools (Hyman \& Sturm, 2008; Koltsova, 2007; Mazilov, 2006; Yurevich, 1999, 2005, 2009; Zhdan, 2007). The key idea of the "old crisis" discourse was that various schools and traditions in psychology lack cohesion and integrative efforts. As a result there is hardly any concept or theory that is accepted and understood in the same way by everybody in the scientific community. Psychological academia is scattered and disunited, and this condition stops it from progressing further. Epistemological problems, although discussed, were and 
are considered by most authors in the context of this disunity and are understood explicitly or implicitly as spawned by it.

However, we believe that there is every reason to assume that disunity is no longer a problem for mainstream scientific psychology and that the crisis of competing theories has largely been overcome (Mandler, 2011). We assume that this development was a natural consequence of the fact that in the second half of the 20th century in developed countries psychology became a mass profession in a globalizing world that required the development of common standards for professional practice and education (Mironenko, 2008). The contemporary discourse of the crisis includes discussion of epistemological problems as well as did discourse about the old crisis, and these problems are largely the same, but the factor causing the aggravation of these problems is no longer the disunity of great schools in psychology.

From time to time, a discourse on a crisis arises in the literature that gives grounds for the idea of a permanent, on-going crisis. However, we believe that regarding periods of that discourse arousal as different crises is more meaningful and constructive than the idea of one, continuing crisis. This change allows us to pass on from discussing perennial, intractable ontological problems of psychology to finding ways to overcome contemporary problems.

\section{The temporal and spatial scope of the crisis}

We fully agree with the assessment of the current state of psychological science as a crisis, but we think that the current crisis (a) does not cover the entire period of the 20th century and (b) at present is not limited to psychology; its roots should be sought in an area not limited to the history of psychological science.

We assert that it was not until the late 1980s that the first signs of the contemporary crisis appeared and that complaints about the mainstream methodology started to be constantly discussed in the literature. The word crisis along with psychology has appeared fifty times in the titles of publications on psychology listed in Scopus since 1966. Of these, 21 are not about the methodological crisis in psychology (they refer to crisis and trauma psychology, for example). The resulting 29 publications, which dwell on the methodological crisis in psychology, are distributed evenly, 1 or 2 each year beginning in 1987. However, from 1966 to 1987 there is not a single article on this crisis. Since 1987 papers on the methodological crisis in psychology have appeared regularly. We consider the main manifestation of this crisis to be the fact that this discourse has formed in the literature. Thus, we'll proceed below to discover the causes of the contemporary crisis. We start with the assumption that the crisis occurred in the last decades of the 20th century.

Another important issue is that we assume that currently we are witnessing a general crisis in human and social sciences, including psychology. Therefore we believe that the analysis of the causes and manifestations of the current crisis in psychology can benefit if it is not limited to the history of methodological thinking in psychology and psychological studies in the 20th century.

The general crisis in the social sciences has been clearly discussed in the literature since the late 1980s (Auerbach, 2006; Batygin, 2004; Oak, 2007). However, this discourse has not yet received sufficient attention from psychologists. 
We believe that considering the actual crisis of psychology as part of a general crisis of social sciences and humanities will allow us to reveal the nature of the crisis and to separate the factors generating the crisis from the perennial problems and contradictions in psychology (between applied and academic science, for example).

In the social and humanitarian disciplines, perhaps the most striking manifestations of the crisis we encounter today are in sociological science. Like psychology, in the last decades sociology has been experiencing complaints about its conditions, which have often been characterized as critical. Through the 1990s and across the millennium years, repeated concerns were expressed about the discipline's decline (Cole, 2001; Turner \& Turner, 1990). The discourse of crisis in sociology has significantly intensified since 2007 as a result of the works of Back (2012), Crompton (2008), Gane (2011), McKie \& Ryan (2012), Savage \& Burrows (2007), Webber (2009), and others. Between January 2007 and November 2013 the word "crisis" along with "sociology" appeared 27 times in the titles of publications on social sciences listed in Scopus.

\section{The causes and determinants of the contemporary crisis in sociological discourse}

In general, the frame of crisis discourse in sociology has much in common with debates in psychology. Both sciences are full of complaints about empirical, theoretical, and practical issues, and in recent decades the tension of the debates has increased significantly.

Is it just a coincidence that two sciences whose subject domains overlap are experiencing separate crises at the same time? That seems highly unlikely. We argue that contemporary crises in the two sciences not only proceed in a similar manner but have common origins and common causes. Let us consider the analysis of the crisis in sociology; perhaps we will find ideas that help us to see anew the crisis in our own science and to discover its causes.

The causes and determinants of the current crisis constitute a major part of the crisis discussions in the sociological literature. There are several approaches to explaining the contemporary crisis in sociology:

1) The "traditional" explanation in terms of "old diseases"

2) The "institutional" explanation in terms of current bureaucratic organization and the institutional arrangement of sociological science

3) The "historical" explanation in terms of radical changes in social life that challenge sociological research with new realities

Although the first two explanations are to a large extent similar to explanations for the crisis in psychology, the third one seems not to be so common and deserves our close attention.

The historical explanation focuses on changes in social, economic, political, and cultural realities that produce new structures and institutions and therefore constitute a major challenge to sociology to cope with these transformations with adequate methodological tools. Changes in theory arise from the clash between the 
changing structures of scientists' reality and preexisting theories. The discourse on radical social changes constitutes a significant part of contemporary sociological debates on global social change and the related methodological challenge, which contemporary sociology still fails to meet.

According to the theories of Beck (2000), Giddens (2007), Lash (2009), Urry (2000), and others, we are living in a world that is dramatically different from the one assessed in earlier sociological theories, which are now unsuitable for the analysis of the new social reality. It is suggested that contemporary sociology is confronted with "a newly coordinated reality, one that is open, processual, non-linear and constantly on the move" (Adkins and Lury, 2009, p. 16). Lash argues that in the 21 st century we are facing a "social reality of global flows, mobilities, and uncertainties" (2009, p. 185). In these conditions the classical approach of social theory centering on the question "How is society possible?" - becomes irrelevant because it presupposes a conception of society as a real social phenomenon. For Lash, "It is no longer a question of finding the conditions of security of the social but being attentive to and describing this uncertainty" (p. 185).

Beck calls for a new type of sociological imagination that is needed for understanding the contemporary shape of global society. For Beck (2000), a "second modernity" emerged in the late 20th century. This phenomenon necessitates the embrace of otherness and a cosmopolitan vision for sociology. He argues that sociological analysis must move beyond the notion of a territorially bounded society because of the impact of mobility, globalization, and interdependence on social formations. It seems that it is no longer a question of finding the stable characteristics of the "social" but rather being attentive to the uncertainty that undermines the usual modes of thinking about society.

As for the challenge of the applied value of sociology, should we be surprised that academic science, which has failed to grasp reality because of the lack of adequate tools, is less useful for practice than applied research, which is less theoretically coherent but more responsive? It is plausible to suggest that if sociologists could enter the public discourse with a convincing and consistent vision of the social world and have a proper methodological toolbox to offer, they would become an essential part of society's development.

As we have seen, in sociology the idea that the cause of the crisis is a radical change of the very subject of science is discussed. The fact that in psychology such ideas are hardly conceived of may be the result of psychology's still being oriented mainly to comprehending the universal nature of the human. Meanwhile the time has come to realize that it is no longer a question of finding the stable characteristics of "the human" but rather being attentive to the uncertainty that undermines the usual modes of thinking about "the human.

\section{Comprehension of culture in psychology the contemporary crisis}

The contemporary crisis in psychology is due to changes in social reality, the scale and speed of which the old concepts cannot comprehend. As has repeatedly been noted in the literature (Castro \& Lafuente, 2007; Marsella, 2012; Moghaddam, 1987; Rose, 2008), 20th-century mainstream psychology developed on the basis, first, of 
assessments of the personality of a human belonging to contemporary Western culture and, second, psychological practices of culturing traits sought after in Western culture - These psychological characteristics acquired the status of universality in mainstream psychology, as exemplified by the concept of "universal human values." Because it took a Western native for a human in general, mainstream psychology is dominated by an implicit tendency to blur boundaries between human culture and human nature and to perceive both as basically static. Culture is regarded here as a kind of superstructure on the foundation of biology, and the unity of nature and culture in humans is considered as somewhat indivisible and forever given and specified. Within the context of this mythology, addressing the issue of the biological bases of psychological features is perceived as reductionism, and defining differences between animal and human, as a plea for cruelty to animals.

Such a metaphysical approach does not fit the reality of the contemporary, transforming multicultural world. The unity of nature and culture in humans is based not only on affinities but also on contradictions, and these contradictions account for the dialectics of change and development, both cultural and biological. Rose (2013) rightly notes that human sciences today have to rethink their relation to biology, as the successful development of biology in the 21st century has opened the possibility to consider it not as a limitation and fatal predetermination but rather as an opportunity and potential for development. Still more necessary for human sciences today is to rethink their relation to culture. A shift is needed from fixation on static concepts and implicit theories of immutable human nature to the idea of humans as infinitely changing creatures because culture is, primarily, the ability to change, the speed and extent of changes being unique for humans among other living beings.

Definitely, humans are animals. However, they are different from other animals because they have culture and the ability to adapt socioculturally. Such adaptations are the most rapid and radical in nature; they include not only adaptation to the environment but also the possibility of changing the environment and oneself. Contemporary cultural psychology attaches great importance to language acquisition and practices and pays a great deal of attention to the early stages of human language and conscience development and to mechanisms that provide entrance into the culture for an infant. However, (it's not a result, it's a paradox. Искажен смысл. Не в результате, а вопреки выше сказанному ок) we can find hardly any attempts to answer the question What is the difference between the communication processes in which the human baby and the animal cub are involved with their mothers? Moreover, in oral discussions, this question is usually perceived as irrelevant and inappropriate and as one for which there can be no clear, intelligible answer.

Meanwhile, some answers have been suggested (Mironenko, 2009). The signals that animals use in communication are comprehensible to all representatives of the species, while human languages are different (Leontiev, 1965/1981; Porshnev, 1974). Human language is fit for one task in addition to message transmission: withholding information from outsiders. In places of the compact residence of different cultures, such as the Caucasus, many languages exist in a small area. As a result, cultures do not mix; they retain their individual identity. Signals of human language are conditional and culturally specified; their connection to reality is me- 
diated by culture. This is an essential feature of human language that distinguishes it from the "language" of animals from the first moments of life.

Another basic difference is that the signals animals use in communication are always directly related to vital needs and emotions, while human language provides not only orientation in the environment but also social interaction and survival of the individual and the group. Here we find conventional signs, and the relationship of the object and the sign is no longer a direct and inseparable one (Leontiev, 1965/1981; Vygotsky, 1997). Here the link between the object and the subject's attitude toward it is also not syncretic. Such a link provides an opportunity for reflection the possibility of developing consciousness and self-awareness. Through language, a new type of reality emerges, one composed of conventional signs and conventional rules of operating on them, and, with the ability to operate and create plans in this new sign reality, active transformation of the material environment becomes possible.

In the mainstream discourse, the fact is virtually neglected that commonly quoted Vygotsky counterposed drastically higher mental functions, which he called cultural and believed to be specific only to humans, to the "natural" functions, which both humans and animals have. Vygotsky is popular mainly among specialists in the "linguistic turn" in cultural psychology ${ }^{1}$ but perhaps the most striking example of the development of his ideas is found in neuropsychology, in Vygotsky's colleague A. R. Luria's theory of the dynamic brain localization of higher mental functions (Luria, 1962, 1963). Luria proved that unlike "natural" functions, which are linked to specific brain structures, higher mental functions are organized as chains of conditional reflexes that are receptive to dynamic transformations and substitutions of brain units.

The implicit idea of cultural differences as being somewhat superficial, not affecting the basics of the human psyche, does not allow psychological science to reflect social reality adequately and to be useful to society in an age of tremendous speed and scale in cultural transformations. This type of psychology does not fit the reality of the contemporary multicultural world either for theoretical assessment or, even more important, for practice. A most important cause of the crisis in mainstream psychology is the confusion of ideals and values we are witnessing in the contemporary multicultural world ; in this world, people have to understand each other and interact in situations of uncertainty and in a mix of civilizations with a multiplicity of values. Of special importance for understanding the problem is the moral conflict that arises in the course of interactions among people who belong to cultures embodying incompatible values and reference points (Mironenko, 2013). This kind of situation is not new or previously unknown in human history. Today, however, it is becoming:

- ubiquitous, whereas previously relatively constant contacts among communities with different cultural-moral orientations were confined to certain areas where cultural communities lived in close proximity

1 Though interpretations of Vygotsky's ideas in the international literature are multiple and versatile (Dafermos, 2015). 
- relatively constant, whereas previously it was intermittent, because even in those places where various cultural communities lived in close proximity "intercultural" communication was confined strictly to specific kinds of interaction

- universal, whereas previously such contacts were confined and entrusted to specially trained people, and in each culture there were rules and norms for communication with strangers and such contacts were monitored by the community and generally known

Today intercultural communication takes place everywhere and all the time; everyone is drawn into it, and rules are absent. In this kind of situation it may be expected that the more certain people are of the absoluteness of the moral values to which they adhere, the more frequently intercultural conflicts will occur and the graver their consequences will be. The greatest danger in a multicultural world is a slide from dialogue to confrontation and conflict. And this is precisely the result when one of the parties has unshakable confidence in its own knowledge of moral truths and in its right to judge those who do not share these "truths."

The problem of values and moral reference points is indeed a problem of vital urgency for contemporary society. It therefore seems not only useless but extremely dangerous to adopt a prejudiced approach to the study of this problem and to replace scientific investigation by faith in the infallibility of one's own ideals and objective analysis by missionary appeals and a search for justifications and accusations - a matter regarding which contemporary mainstream psychology is often at fault.

The problem of the biology-culture relation in human nature is a perennial problem of psychology; it permeates the entire history of our science. The development of psychology has always been quite dramatic, replete with methodological discussions, if only because of the position of psychology at the intersection of natural sciences and humanities, which are different in their methods. The discourse of the "understanding" (humanitarian, teleological) psychology versus the "explaining" psychology (clinging to natural sciences, causal) entails endless debate over the criteria for obtaining and verifying knowledge and over the adequacy of that knowledge.

A characteristic feature of the current development of this discourse is that there are fewer appeals for the destruction of the opponent, as in the discourse of the "old" crisis (Vygotsky, 1997), than for peaceful disengagement. The question of whether psychology should split into several distinct sciences is much discussed in the literature (Driver-Linn, 2003; Hunt, 2005; Mironenko, 2008; Walsh-Bowers, 2010; Zittoun et al., 2009). Fairly strong arguments can be provided in support of each solution. On the one hand, the previous few decades have witnessed the intensive development of psychological research at the intersection with other sciences, especially biological sciences, which were developing particularly rapidly at the turn of the millennium. The development of new concepts and new research methods mutually suitable for the natural sciences and for psychology and the accumulation of a large amount of new empirical data naturally entail a tendency to healthy differentiation (Bower, 1993; McNally, 1992; Mironenko, 2008); this process follows the general tendency to differentiation in the course of the historical 
development of science. ${ }^{1}$ On the other hand, strong arguments are presented in favor of psychology's maintaining the status of an integrated science at the intersection of natural sciences and humanities: "Defining tensions make psychology a dynamic pluralism whose strands must collide and interact, generating both novel scientific discovery and emergent perspectival shifts in theory and areas of major interest. Because psychology is a single discipline, emerging out of these interdependent tensions" (Hunt, 2005, p. 372).

Is psychology able to sustain that dynamic pluralism? Whatever the boundaries of psychology may be, to overcome the contemporary crisis it has to break down the stereotype of the essential stability of human nature and of the pure unity of human biology and culture.

\section{References}

Adair, J. G., \& Vohra, N. (2003). The explosion of knowledge, references, and citations: Psychology's unique response to a crisis. American Psychologist, 58(1), 15-23. doi: 10.1037/0003066X.58.1.15

Adkins, L., \& Lury, L. (2009). What is the empirical. European Journal of Social Theory, 12, 5-20. doi: $10.1177 / 1368431008099641$

Auerbach, B. (2006). Publish and perish. Actes de la Recherche en Sciences Sociales, 4, 75-92. doi: $10.3917 /$ arss. 164.0075

Back, L. (2012). Live sociology: Social research and its futures. Sociological Review, 60(S1), 18 39. doi: 10.1111/j.1467-954X.2012.02115.x

Batygin, G. S. (2004). Social scientists in times of crisis: The structural transformations within the disciplinary organization and thematic repertoire of the social sciences. Studies in East European Thought, 56(1), 7-54. doi: 10.1023/B:SOVI.0000007364.01092.90

Beck, U. (2000). The cosmopolitan perspective: Sociology of the second age of modernity. British Journal of Sociology, 51(1), 79-105. doi: 10.1080/000713100358444

Bower, G. H. (1993). The fragmentation of psychology? American Psychologist, 48(8), 905-907. doi: 10.1037/0003-066X.48.8.905

Castro, J., \& Lafuente, E. (2007). Westernalization in the mirror: On the cultural reception of Western psychology. Integrative Psychological and Behavioral Science, 41(1), 106-113. doi: 10.1007/s12124-007-9013-z

Cole, S. (Ed.). (2001). What's wrong with sociology? New York: Transaction.

Crompton, R. (2008). Forty years of sociology: Some comments. Sociology 42(6), 1218-1227. doi: $10.1177 / 0038038508096942$

Dafermos, M. (2015). Critical reflection on the reception of Vygotsky's theory in the international academic communities. In B. Selau \& R. Fonseca de Castro (Eds.), Cultural-Historical Theory: Educational Research in Different Contexts (pp.19-38). Porto Alegre: EDIPUCRS.

Driver-Linn, E. (2003). Where is psychology going? Structural fault lines revealed by psychologists' use of Kuhn. American Psychologist, 58(4), 269-278. doi: 10.1037/0003-066X.58.4.269

Essex, C., \& Smythe, W. E. (1999). Between numbers and notions. A critique of psychological measurement. Theory and Psychology, 9(6), 739-767. doi: 10.1177/0959354399096002

$1 \quad$ For example, chemistry and physics separated in the 18th century, when the number of methods and recognized facts specific to each topped the number of mutually accepted methods and facts; in these circumstances, further development required the splitting of a previously integrated science. 
Gane, N. (2011). Measure, value and the current crises of sociology. Sociological Review, 59(S2), 151-173. doi: 10.1111/j.1467-954X.2012.02054.x

Giddens, A. (2007, November/December). Doubting diversity's value. Foreign Policy, 87-88.

Goertzen, J. R. (2008). On the possibility of unification: The reality and nature of the crisis in psychology. Theory and Psychology, 18(6), 829-852. doi: 10.1177/0959354308097260

Grace, R. C. (2001). On the failure of operationism. Theory and Psychology, 11(1), 5-33. doi: $10.1177 / 0959354301111001$

Hunt, H. T. (2005). Why psychology is/is not traditional science: The self-referential bases of psychological research and theory. Review of General Psychology, 9(4), 358-374. doi: 10.1037/1089-2680.9.4.358

Hyman, L., \& Sturm, T. (2008). Crisis debates in psychology: Causes, contexts, and consequences. Berlin: Max Planck Institute for the History of Science. Retrieved from http://www.mpiwgberlin.mpg.de/PDF/CrisisWorkshop_Abstracts.pdf

Koltsova, V. A. (2007). Actual methodological problems of contemporary psychological science in Russia. Psikhologicheskii Zhurnal [Psychological Journal], 28(2), 5-18.

Lash, S. (2009). Afterword: In praise of the a posteriori: Sociology and the empirical. European Journal of Social Theory, 12, 175-187. doi: 10.1177/1368431008099646

Leontyev, A. N. (1965). Problems of Psychic Development . Moscow: Mysl.

Leontiev, A. N. (1981). Problems of psychic development. Moscow: Moscow State University Publications (Original work published 1965).

Luria, A. R. (1962). Higher cortical functions in man. Moscow: Moscow University Press.

Luria, A. R. (1963). Restoration of function after brain injury. New York: Pergamon Press.

Mandler, G. (2011). Crises and problems seen from experimental psychology. Journal of Theoretical and Philosophical Psychology, 31(4), 240-246. doi: 10.1037/a0023968

Marsella, A. (2012). Psychology and globalization: Understanding a complex relationship. Journal of Social Issues, 68(3), 454-472. doi: 10.1111/j.1540-4560.2012.01758.x

Mazilov, V. A. (2006). Theoretical problems of psychology at the beginning of the 21st century. Psikhologicheskii Zhurnal [Psychological Journal], 27(1), 23-34.

McKie, L., \& Ryan, L. (2012). Exploring trends and challenges in sociological research. Sociology, 46(6), 1-7. doi: 10.1177/0038038512452356

McNally, R. J. (1992). Disunity in psychology: Chaos or speciation? American Psychologist, 47, 1054. doi: 10.1037/0003-066X.47.8.1054.a

Michell, J. (2003). The quantitative imperative. Positivism, naive realism and the place of qualitative methods in psychology. Theory and Psychology, 13(1), 5-31. doi: 10.1177/0959354303013001758

Mironenko, I. A. (2007). What causes doubts in the progress of psychological science? Metodologia i Historia Psychologii [Methodology and History of Psychology], 3, 94-107.

Mironenko, I. A. (2008). The "crisis" of psychology: Is it general or local? Voprosy Psikhologii [Issues in Psychology], 4, 119-127.

Mironenko, I. A. (2009). The past, the present and the future of the Russian school of comparative psychology. Metodologia i Historia Psychologii [Methodology and History of Psychology], $4(2), 45-59$.

Mironenko, I. A. (2013). The problem of morality in contemporary Russian psychology. Russian Studies in Philosophy, 51(4), 51-63. doi: 10.2753/RSP1061-1967510403

Moghaddam, F. M. (1987). Psychology in the three worlds: As reflected by the crisis in social psychology and the move toward indigenous third-world psychology. American Psychologist, 42(10), 912-920. doi: 10.1037/0003-066X.42.10.912

Oak, E. (2007). Quo vadis the social sciences? Appropriating ground in the indeterminacy of knowledge crisis: The role of qualitative social work research. International Journal of the Interdisciplinary Social Sciences, 1(5), 69-78. 
Porshnev, B. (1974). On the dawn of human history. Moscow: Nauka.

Rose, N. (2008). Psychology as a social science. Subjectivity, 23, 1-17. doi: 10.1057/sub.2008.30

Rose, N. (2013). The human sciences in a biological age. Theory, Culture and Society, 30(1): 3-34. doi: $10.1177 / 0263276412456569$

Savage, M., \& Burrows, R. (2007). The coming crisis of empirical sociology. Sociology, 41(5): 885-899. doi: $10.1177 / 0038038507080443$

Schwarz, M. (2009). Is psychology based on a methodological error? Integrative Psychological and Behavioral Science, 43(3), 185-213. doi: 10.1007/s12124-009-9089-8

Toomela, A. (2007). Culture of science: Strange history of the methodological thinking in psychology. Integrative Psychological and Behavioral Science, 41, 6-20. doi: 10.1007/s12124-007 $-9004-0$

Turner, S., \& Turner, J. (1990). The impossible science: An institutional analysis of American sociology. Newbury Park, CA: Sage.

Urry, J. (2000). Sociology beyond societies: Mobilities for the twenty-first century. London: Routledge.

Valsiner, J., (2010). Integrating psychology within the globalizing world: A requiem to the postmodernist experiment with wissenschaft. Integrative Psychological and Behavioral Science, 43(1), 1-21. doi: 10.1007/s12124-009-9087-x

Veresov, N. (2010). Forgotten methodology: Vygotsky's case. In A. Toomela \& J. Valsiner (Eds.), Methodological thinking in psychology: 60 years gone astray? (pp. 267-295). Charlotte, NC: Information Age Publishing.

Vygotsky, L. S. (1997). The collected works of L. S. Vygotsky, Vol. 3: Problems of the theory and history of psychology (R. van der Veer, Trans.). New York: Plenum.

Walsh-Bowers, R. (2010). Some social-historical issues underlying psychology's fragmentation. New Ideas in Psychology, 28, 244-252. doi: 10.1016/j.newideapsych.2009.09.018

Webber, R. (2009). Response to "The coming crisis of empirical sociology": An outline of the research potential of administrative and transactional data. Sociology, 43(1), 169-178. doi: 10.1177/0038038508099104

Yurevich, A. V. (1999). The systemic crisis in psychology. Voprosy Psikhologii [Issues in Psycho$\log y], 2,3-12$.

Yurevich, A. V. (2005). Psychology and methodology. Moscow: IP RAS.

Yurevich, A. V. (2009). Cognitive frames in psychology: Demarcations and ruptures. Integrative Psychological and Behavioral Science, 43(2), 89-103. doi: 10.1007/s12124-008-9082-7

Zhdan, A. N. (2007). Concerning theoretical problems of general psychology. Voprosy Psikhologii [Issues in Psychology], 6, 137-142.

Zittoun, T., Gillespie, A., \& Cornish, F. (2009). Fragmentation or differentiation: Questioning the crisis in psychology. Integrative Psychological and Behavioral Science, 43(2), 104-115. doi: $10.1007 / \mathrm{s} 12124-008-9083-6$

Original manuscript received February 18, 2015

Revised manuscript accepted July 30, 2015

First published online September 30, 2015 